Ferreira, RS, Lopes, NMD \& Carvalho, PHV. (2020). Composition of airport pavements and their particularities. Research, Society and Development, 9(7):1-16, e180972510.

\title{
Composição dos pavimentos aeroportuários e suas particularidades
}

\section{Composition of airport pavements and their particularities}

Composición de pavimentos aeroportuarios y sus particularidades

Recebido: 03/01/2019 | Revisado: 27/01/2019 |Aceito: 01/05/2020 | Publicado: 03/05/2020

Ramon de Souza Ferreira

ORCID: http://orcid.org/0000-0002-1629-1741

Universidade Federal dos Vales do Jequitinhonha e Mucuri, Brasil

E-mail:marromsf@hotmail.com

Nádia Maria Dias Lopes

ORCID: https://orcid.org/0000-0003-2676-0182

Universidade Presidente Antônio Carlos, Brasil

E-mail: nadiamariadiaslopesfies@gmail.com

Paulo Henrique Vieira de Carvalho

ORCID: https://orcid.org/0000-0002-2316-9592

Universidade Presidente Antônio Carlos, Brasil

E-mail: phvcengcarvalho@yahoo.com.br

\section{Resumo}

Esse trabalho teve como objetivo expor, analisar e avaliar a composição dos pavimentos aeroportuários com suas particularidades de dimensionamento e construção. Através de documentação indireta, foi realizada uma pesquisa bibliográfica identificando as diferenças entre os pavimentos aeroportuários e os rodoviários em relação à sua estrutura e engenharia. Primeiramente foi apresentada a estrutura de um pavimento de forma geral, tipos de pavimentos e revestimentos. Posteriormente foram analisados os pavimentos aeroportuários brasileiros observando sua metodologia de dimensionamento que se orienta seguindo padrões internacionais. Em seguida foram estabelecidas as relações entre os pavimentos aeroportuários e os rodoviários e identificadas semelhanças e diferenças entre as duas modalidades. Por último, foi apresentada a eficiência da estrutura de um pavimento aeroportuário e suas particularidades.

Palavras-chave: Pavimentos aeroportuários; Dimensionamento; Estrutura. 


\begin{abstract}
This work aimed to expose, analyze and evaluate the composition of airport pavements with their design and construction peculiarities. Through indirect documentation, a bibliographic search was carried out identifying the differences between airport and road pavements in relation to their structure and engineering. First, the structure of a pavement was presented in general, types of pavements and coverings. Subsequently, Brazilian airport pavements were analyzed, observing their dimensioning methodology, which is oriented according to international standards. Then, the relationships between airport and road pavements were established and the similarities and differences between the two modalities were identified. Finally, the efficiency of an airport pavement structure and its particularities was presented.
\end{abstract}

Keywords: Airport floors; Sizing; Structure.

\title{
Resumen
}

Este trabajo tuvo como objetivo exponer, analizar y evaluar la composición de los pavimentos aeroportuarios con sus peculiaridades de diseño y construcción. A través de la documentación indirecta, se realizó una búsqueda bibliográfica para identificar las diferencias entre los pavimentos de aeropuertos y carreteras en relación con su estructura e ingeniería. Primero, se presentó la estructura de un pavimento en general, tipos de pavimentos y revestimientos. Posteriormente, se analizaron los pavimentos aeroportuarios brasileños, observando su metodología de dimensionamiento, que está orientada de acuerdo con los estándares internacionales. Luego, se establecieron las relaciones entre los pavimentos de aeropuertos y carreteras y se identificaron las similitudes y diferencias entre las dos modalidades. Finalmente, se presentó la eficiencia de una estructura de pavimento aeroportuario y sus particularidades.

Palabras clave: Pavimentos aeroportuarios; Dimensionamiento; Estructura.

\section{Introdução}

Em decorrência do crescimento da demanda de serviços aeroportuários, diversos países incluindo o Brasil foram obrigados a aumentar e melhorar seus aeródromos que são comumente conhecidos como aeroportos de pequeno porte e campos de aviação. Com o aumento de passageiros e viagens foi necessário desenvolver aeronaves mais potentes e maiores que pudessem levar mais pessoas e cargas. Consequentemente, é importante criar pistas mais robustas que conseguissem suportar esse aumento no trânsito e no peso 
transportado pelas aeronaves se tornou imprescindível.

Diante de tal crescimento, o Brasil necessitou de aporte financeiro e optou por buscar investimentos em parcerias público-privadas para equipar seus aeródromos e alcançar altos níveis de qualidade em suas viagens. Assim, foi necessário melhorar toda a infraestrutura aeroportuária para suportar o crescimento dessa demanda (INFRAERO, 2016).

Os padrões de pistas são definidos pela Federal Aviation Administration (FAA) e levam em conta a quantidade de trânsito e os tipos de aeronaves que irão utilizar as pistas. Essa agência publica relatórios com o objetivo de auxiliar construtores e projetistas para que possam dimensionar os pavimentos da melhor forma possível. Como o Brasil não possui uma agência responsável por estudos desse tipo, a Agência Nacional de Aviação Civil (ANAC) adota os estudos da FAA.

O dimensionamento das pistas orientado pela FAA trata da espessura das camadas do pavimento que será utilizado, tipo de pavimento, tipo de revestimento, resistência do subleito, pressão interna nos pneus das aeronaves e o método de avaliação utilizado para definir esses parâmetros. A pavimentação dos aeroportos é dimensionada de forma totalmente diferente em relação à pavimentação rodoviária. Diante disso, esse trabalho se justifica pela apresentação das diferenças na composição e dimensionamento dos pavimentos aeroportuários. Ao diferenciarem, eles apresentam características que visam atender os objetivos para os quais foram criados. É essencial então apresentar essas diferenças e seus objetivos para que as características positivas possam influenciar em ambos.

Esse trabalho foi realizado por meio de pesquisa bibliográfica com documentação indireta. Trata-se do estudo de materiais já existentes e publicados em revistas, jornais, livros entre outros. Através de um estudo qualitativo foi possível analisar a composição dos pavimentos com ênfase nos aeroportuários. Também foram analisados circulares emitidos por órgãos responsáveis por estudos sobre pavimentação aeroportuária e suas particularidades (Gil, 2009, Pereira et al. 2018).

Com isso este trabalho tem como objetivo geral identificar qual a composição dos pavimentos aeroportuários juntamente com suas particularidades e diferenças em comparação com os pavimentos rodoviários. Os objetivos específicos são, identificar os tipos de pavimentos existentes, apresentar a composição de pavimentos asfálticos, apontar os tipos de revestimentos e expor as particularidades do pavimento aeroportuário em detrimento ao pavimento rodoviário. Através desse estudo é possível perceber que mesmo utilizando os mesmos materiais, a concepção dos pavimentos rodoviários e, aeroportuários parte do mesmo princípio de engenharia, mas, no fim se mostram bem diferentes devido às características que 
cada modalidade requer.

\section{Pavimentos}

\subsection{Estrutura de um pavimento}

O pavimento é uma estrutura constituída por camadas de vários materiais preparados ou beneficiados (Vicentini, 2017). As principais camadas de um pavimento são o revestimento de base asfáltica, base e subleito. Elas também podem ser divididas em subcamadas. De acordo com Balbo (2007), o pavimento contém as camadas apresentadas a seguir e na Figura 1:

$>$ Revestimento: camada responsável por receber as cargas verticais e horizontais que são provenientes do tráfego, e transmitem às camadas inferiores. Responsável por melhorar a superfície de rolamento.

$>$ Base: essa camada é destinada a receber todo tipo de esforços realizados pelo tráfego e o distribuir.

$>$ Sub-base: essa parte do pavimento tem a mesma finalidade da base, é feita acima do subleito ou também pode ser feita como reforço para o subleito.

$>$ Reforço do subleito: essa camada possui espessura que pode ser variada visando melhorar o desempenho do subleito.

Subleito: camada mais profunda para a construção do pavimento. É a fundação do pavimento. Consiste no material existente no local da obra.

Dependendo da intensidade e do tipo de tráfego, do solo existente e da vida útil do projeto, o revestimento poderá ser feito tendo uma camada de rolamento e outras camadas intermediárias ou de ligação. Mas nos casos mais comuns, utiliza-se apenas uma camada de mistura asfáltica tipo revestimento.

O asfalto pode ser fabricado em usina específica (misturas usinadas), fixa ou móvel, ou preparado na própria pista (para tratamentos superficiais). Além da forma de produção, os revestimentos também podem ser classificados quanto ao tipo de ligante utilizado: a quente com o uso de concreto asfáltico, o chamado Concreto Betuminoso Usinado a Quente (CBUQ) ou a frio com o uso de emulsão asfáltica de petróleo (EAP).

O CBUQ é o mais empregado no Brasil. Trata-se do produto da junção de agregados de vários tamanhos e cimento asfáltico, ambos aquecidos em temperaturas previamente 
escolhidas, de acordo com as características viscosidade-temperatura do ligante.

Mais econômicas, as misturas asfálticas usinadas a frio são indicadas para revestimento de ruas e estradas de baixo volume de tráfego, ou ainda como camada intermediária (com concreto asfáltico superposto) e em operações de conservação e manutenção. Neste caso, as soluções podem ser pré-misturadas e devem receber tratamentos superficiais posteriores.

\subsection{Tipos de pavimento}

Para Bernucci et al., (2006) os pavimentos geralmente são classificados em três tipos, sendo eles: rígidos, semirrígidos e flexíveis.

O pavimento rígido é aquele pouco deformável, constituído principalmente de concreto de cimento. Rompem por tração na flexão, quando sujeitos a deformações (SENÇO, 2008). Segundo apresentado pelo mesmo autor, na confecção dos pavimentos rígidos, os revestimentos são feitos com cimento Portland e sua espessura é obtida através da resistência das placas de concreto e pela resistência das camadas inferiores. Estas recebem o nome de sub-base e subleito. Essas placas podem conter ou não armadura de aço e possuem concreto suficiente para suportar os esforços solicitados.

O pavimento semirrígido é basicamente um pavimento intermediário entre o flexível e o rígido. É constituído através de uma mescla entre os componentes dos outros tipos de pavimentos, como solo e cimento, solo e betume, solo e cal e outras que apresentam melhor resistência à tração (Word Road Association Mondiale de la Route, 2008).

Os pavimentos semirrígidos possuem características parecidas à dos flexíveis, sendo que a base do pavimento é feita com material estabilizado quimicamente, por exemplo: solocal, solo-cimento e brita graduada tratada com cimento (Bernucci, 2008).

Já o pavimento flexível é aquele que quando deformado até certo limite não se rompe. São dimensionados normalmente à compressão e à tração na flexão, provocada pelo aparecimento das bacias de deformação sob as rodas dos veículos, que levam a estrutura a deformações permanentes, e ao rompimento por fadiga. (SENÇO, 2008). Esse pavimento, geralmente, é associado aos pavimentos asfálticos. São feitos com uma camada fina de revestimento, sobre camadas de base, de sub-base e de reforço do subleito, constituídas por materiais granulares, solos ou misturas de solos, sem adição de agentes cimentantes (Ibid, 2008).

Pavimentos flexíveis são os pavimentos em que o revestimento é feito através de uma 
mistura de ligantes asfálticos e de agregados. Esse pavimento é feito com revestimento, base, sub-base, reforço de subleito (caso seja necessário) e subleito.

O revestimento pode ser feito com a camada de rolamento e, algumas camadas intermediárias, chamadas de blinder. De acordo com os materiais disponíveis ou o tráfego da pista, algumas camadas podem ser excluídas.

\subsection{Tipos de revestimento}

O revestimento como sendo a capa de rolamento consiste na camada do pavimento que irá receber toda a ação do tráfego. Ela tem a função de melhorar o tráfego proporcionando conforto e segurança, além de durabilidade. O revestimento é executado normalmente com espessura variável entre 2 a $5 \mathrm{~cm}$ por camada e pode ser um problema econômico já que seu preço acaba sendo maior que o das demais camadas (Senço, 2001).

Por ser a camada mais elevada do pavimento, o revestimento deve ter uma execução bem elaborada e detalhada, visto que existem alguns esforços que irão atuar diretamente nessa camada, sendo: esforços tangenciais, pressão de impacto, longitudinais (frenagem e rolamento), transversais (curvas) e de sucção (Ibid, 2001).

Para Durán (2015), o revestimento consiste na camada mais superficial, que objetiva proteger todas as camadas que estão abaixo contra a deterioração, causada pelo tráfego, e por esse motivo se destina a melhorar a segurança de rolamento e a comodidade.

O revestimento tem o objetivo de receber cargas (dinâmicas ou estáticas) sem sofrer maiores deformações ou até desagregação dos componentes de sua estrutura ou ainda, de perder sua compactação. Desse modo, precisa ser constituído por materiais aglutinados corretamente como os tratamentos betuminosos superficiais e as misturas asfálticas no geral (Balbo, 2007).

Segundo Brochado (2014), a camada de revestimento possui espessura variada, exercendo funções dos critérios próprios do projeto ou também em função do tráfego previsto. Para as vias simples são utilizadas espessuras de até $5 \mathrm{~cm}$; já para autoestradas pode-se atingir a espessura de $10 \mathrm{~cm}$. Para os tipos de revestimento flexível são dentre eles os Tratamentos superficiais simples, duplo e triplo (TSS, TSD, TST), Concreto Betuminoso Usinado a Quente (CBUQ) e Pré misturado a frio (PMF).

Para se definir que revestimento será utilizado, o projetista precisa levar em conta a questão econômica e técnica. Para serviços de padrão alto, o revestimento que é mais utilizado é o tipo concreto betuminoso. Em obras de padrão médio utiliza-se o tratamento 
superficial, de preferência triplo. Para os padrões mais baixos, utiliza-se o tratamento superficial ou simples.

Os fatores determinantes para a escolha de um tipo de revestimento em detrimento a outro, segundo Senço (2001), são: o custo, a quantidade e o tipo de tráfego, pó, facilidade de limpeza e segurança, as características físicas como cor, aparência geral, considerações locais especiais como os materiais locais, os tipos existentes e organização de conservação.

\subsection{Transporte aeroviário}

Os meios de transporte são responsáveis por escoar a produção mundial, proporcionar o deslocamento de pessoas, auxiliar e facilitar a logística mundial. Para isso existem mais de uma modalidade e essas atendem cada necessidade de transporte. A modalidade aeroviária é responsável pelo deslocamento mais rápido e pode superar a rodoviária em transporte de maiores cargas por causa do tamanho e velocidade que as aeronaves possam atingir.

\subsection{Pavimentos aeroportuários}

De acordo com a Federal Aviation Administration (FAA, 2007), os pavimentos aeroportuários devem ser capazes de proporcionar segurança ao tráfego de aviões durante pousos e decolagens além de garantir que possam resistir a falhas, grandes cargas mecânicas e intempéries.

Para Durán (2015), as principais patologias verificadas em pavimentos aeroportuários são trincas por fadiga, couro de jacaré, exsudação, trincas de bloco, corrugação, depressão/afundamento, erosão por queima ou combustão, trincas de reflexão, base de concreto, trincas transversais e longitudinais, deterioração por presença de óleo/combustível, remendos, polimento de agregado, desagregação, afundamento da trilha de roda, deformação permanente, empuxo no revestimento, placas de concreto, escorregamento, inchamento e desprendimento.

Essas patologias podem ser corrigidas aplicando reparos de acordo com suas extensões e características. Cabe às empresas que administram os aeródromos a tarefa de manter as pistas de pousos e decolagens - além de outras áreas que contenham pavimentação - livres de patologias e seguras para o tráfego das aeronaves.

Várias empresas administram aeródromos no Brasil. As duas principais são a INFRAERO e o Departamento Aeroviário do estado de São Paulo (DAESP). A INFRAERO 
atua em todos os estados brasileiros administrando 67 aeroportos, 81 unidades de apoio à navegação aérea e 32 terminais de logística de carga. Já o DAESP mantém convênio com a ANAC para administrar 27 aeroportos públicos no estado de São Paulo (GARCIA, 2014).

Segundo Durán (2015), o conjunto de infraestrutura que faz parte do ambiente do local onde existem as dependências do aeroporto é denominado aeródromo. São compostas por duas partes, sendo elas a parte terra e a parte ar.

A parte terra é composta por toda infraestrutura aberta ao público como os edifícios e as instalações que possibilitem o embarque e desembarque dos passageiros e cargas, e os estacionamentos de veículos. A parte ar é restrita ao público e composta pelas estruturas que possibilitam que as aeronaves realizem suas manobras, sendo elas: pista de decolagem, pouso, taxiamento e estacionamento das aeronaves.

\subsubsection{Dimensionamento de pavimento aeroportuário no Brasil}

De acordo com Taffe (2002), o Brasil segue os métodos desenvolvidos pela FAA tanto para novos projetos quanto para reparos de pavimentos aeroportuários. A FAA foi criada nos Estados Unidos da América em 1958 sendo conectada ao Departamento de Transportes e responsável por todos os regulamentos e particularidades ligados a aviação civil.

Segundo Ramos (2017), o Brasil tem seguido as instruções da FAA através dos documentos AC 150/5320-6C (FAA, 1978), AC 150/5320-6D (FAA, 1995), AC 150/5320-6E (FAA, 2009) e AC 150/5320-6F (FAA, 2016). Um fator utilizado para o dimensionamento é através dos tipos de aeronaves e frequências de pousos e decolagens que o aeródromo pretende atender.

Os tipos de aeronaves são divididos em seis tipos e juntamente com a frequência de cada grupo o cálculo é feito. Caso algum tipo não esteja incluso no programa, é possível realizar um novo cálculo através de um grupo denominado Generic que possibilita a inclusão da aeronave pelo seu tipo de trem de pouso (Ramos, 2017).

O Quadro 1 abaixo apresenta a sequência de etapas e procedimentos para realizar o dimensionamento dos pavimentos aeroportuários. 
Quadro 1 - Dimensionamento de pavimento aeroportuário segundo AC 150/5320-6D.

\begin{tabular}{|c|c|}
\hline Etapa & Procedimentos \\
\hline 1 & Identificar a aeronave de projeto como aquela que leve à maior espessura de pavimento. \\
\hline $\begin{array}{l}2 \\
\text { todas a }\end{array}$ & $\begin{array}{l}\text { Obter o peso máximo de decolagem e o tipo de trem de pouso da aeronave de projeto e de } \\
\text { s outras aeronaves que vão utilizar o aeroporto em questão. }\end{array}$ \\
\hline 3 & Obter o número de decolagens anuais previstas para cada aeronave. \\
\hline $\begin{array}{l}4 \\
\text { seu pe } \\
\text { pouso }\end{array}$ & $\begin{array}{l}\text { Obter, para cada tipo de aeronave, a sua carga por roda como o resultado da divisão de } 95 \% \text { do } \\
\text { so máximo de decolagem pelo número de rodas do trem de pouso principal (ou dos trens de } \\
\text { principais, se aplicável). }\end{array}$ \\
\hline $\begin{array}{l}5 \\
\text { consid } \\
\text { projet }\end{array}$ & $\begin{array}{l}\text { Converter o número de decolagens de cada aeronave em termos da aeronave de projeto, } \\
\text { erando-se os fatores de conversão de cada trem de pouso para o trem de pouso da aeronave de }\end{array}$ \\
\hline
\end{tabular}

6 Determinar o número equivalente anual de decolagens da aeronave de projeto com base no número de decolagens de cada tipo de aeronave convertendo para a aeronave de projeto e na relação entre as cargas por roda de cada aeronave e da aeronave de projeto.

$7 \quad$ Empregar ábaco específico de projeto que relaciona o trem de pouso da aeronave de projeto, o tipo de pavimento (rígido ou flexível), o peso máximo de decolagem da aeronave de projeto, a resistência mecânica do solo [através do valor de CBR do subleito (pavimento flexível) ou do coeficiente de reação do subleito ou do sistema subleito/sub-base (pavimento rígido)] e o número equivalente anual de decolagens da aeronave de projeto, para fins de determinação da espessura do pavimento (espessura total de camadas de pavimento flexível ou da placa de concreto de pavimento rígido).

Fonte: Adaptado da FAA (1995).

Por meio deste quadro de dimensionamento é possível obter os melhores resultados na construção do aeródromo. Por levar em conta todos os fatores que possam interferir em sua composição e conservação têm sido usados como regra pelos construtores.

\subsubsection{Relação entre os pavimentos aeroportuários e os rodoviários}

Os pavimentos aeroportuários e os rodoviários possuem algumas semelhanças e diversas diferenças. Ambos são dimensionados baseados nos mesmos critérios, entretanto, é justamente aí que as diferenças entre os dois começam. Enquanto que os pavimentos rodoviários são dimensionados para resistirem a esforços repetitivos e com menores impactos, os pavimentos aeroportuários são feitos justamente com o intuito contrário, suportar menores repetições em vista dos rodoviários e maiores esforços de cargas. Também são maiores as espessuras das camadas dos pavimentos aeroportuários em função da configuração dos trens de pouso das aeronaves, centro de gravidade e seu peso (Yoder \& Witczak Apud Durán, 2015).

Medina \& Motta (2005) realizam uma comparação entre os dois pavimentos com o apontamento das diversas diferenças através da Tabela 1. 
Research, Society and Development, v. 9, n. 7, e180972510, 2020

(CC BY 4.0) | ISSN 2525-3409 | DOI: http://dx.doi.org/10.33448/rsd-v9i7.2510

Tabela 1 - Principais diferenças entre rodovias e aeródromos.

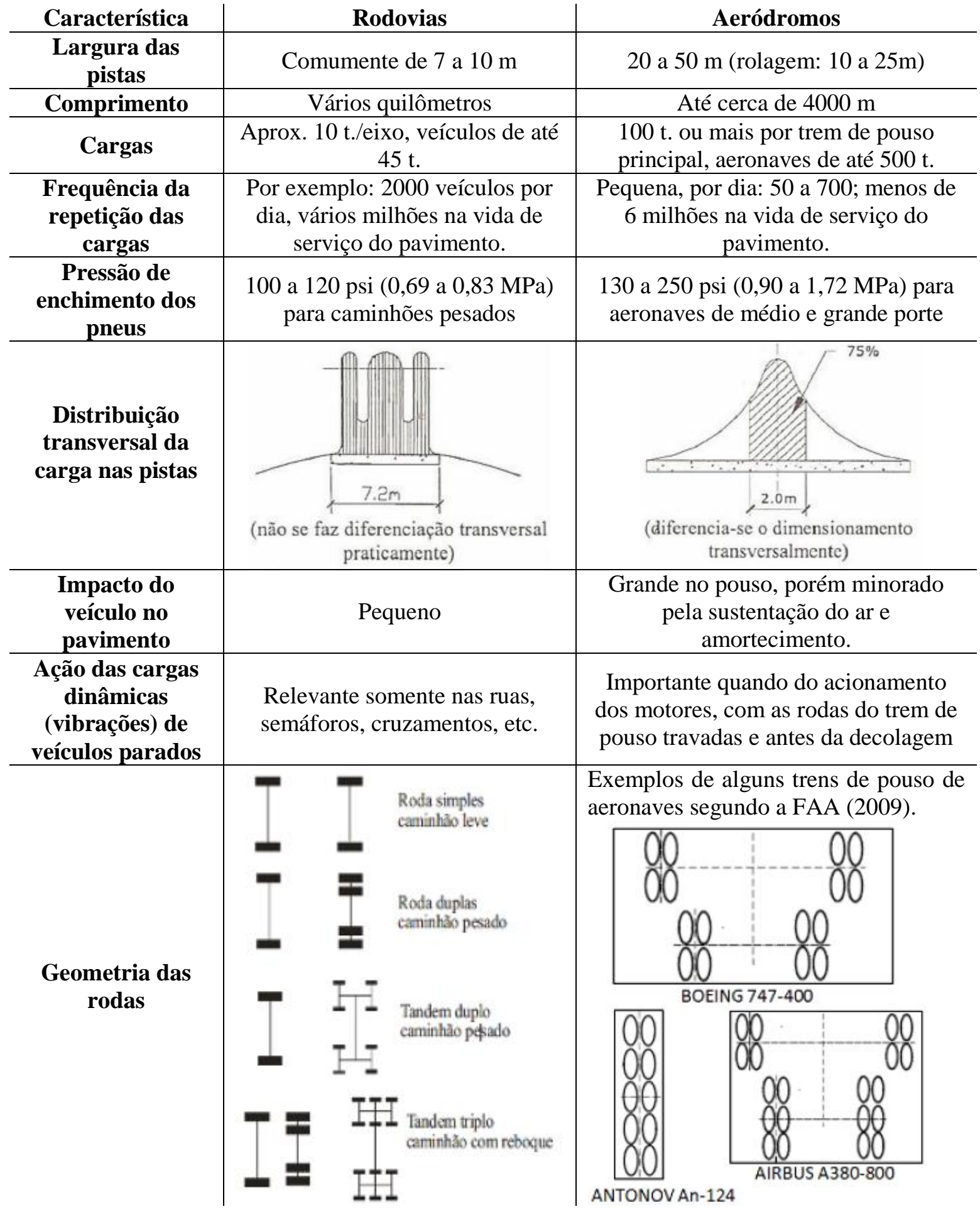

Fonte: Adaptado Durán (2015).

Por ser tratarem de finalidades diferentes, esses pavimentos, mesmo contendo quase que os mesmos elementos apresentam diferenças. É natural que essas diferenças venham suprir as finalidades às quais foram impostas. 


\subsubsection{Eficiência estrutural do pavimento aeroportuário}

De acordo com Durán (2015), os estudos para a construção de um pavimento devem ser extremamente precisos de tal forma que esses pavimentos sejam capazes de suportar o trânsito e o peso das cargas. Para os pavimentos aeroportuários, o estudo é feito baseado nos tipos de cargas levadas pelas aeronaves, frequência de tráfego e tipo de aeronave que usará as pistas.

Os pavimentos de forma geral são concebidos visando atender às demandas de tráfego de acordo com o estudo prévio realizado para sua construção. Nada impede que esse pavimento seja alterado ou melhorado caso ocorra aumento de tráfego ou alteração do tipo de veículos que estarão transitando por ele.

Segundo a International Civil Aviation Administration (ICAO, 2013), o método Aircraft Classification Number / Pavement Classification Number (ACN/PCN) é utilizado para definir as características dos pavimentos aeroportuários. Para a Agência Nacional de Aviação Civil do Brasil (ANAC, 2008), esse método destina-se a pavimentos que irão suportar aeronaves a partir de $5.700 \mathrm{~kg}$, sendo que o ACN determina o efeito da carga que a aeronave exerce quando está na pista e o PCN indica a real capacidade que o pavimento pode suportar independente de qualquer restrição.

De acordo com Gomes (2008), o ACN e o PCN são conjuntos de números já prédefinidos. O ACN é fornecido pelo construtor da aeronave de acordo com as características peso, geometria do trem de pouso e a pressão interna dos pneus. O PCN é o índice de quanto o pavimento suportará para uma aeronave de padrão roda simples e pressão interna dos pneus de 180psi ou 1,25Mpa (megapascal) independentemente do tipo de aeronave.

Para Durán (2015), o PCN pode ser obtido através de avaliação prática ou técnica. Na avaliação prática é adotado um número ACN para a aeronave em um momento mais instável em um aeródromo sem danos estruturais em seu pavimento e aceita-se como PCN o maior valor obtido de ACN encontrado. Já na avaliação técnica é feito o processo inverso. Combinase frequência de pousos e decolagens com peso da aeronave e possíveis cargas que ela carregará e os níveis de tensão admissíveis. De acordo com a ANAC (2008), após identificar a carga admissível, é possível identificar o tipo de aeronave e o valor do seu PCN. O PCN é composto por cinco elementos como consta no Quadro 2. 
Quadro 2 - Elementos formadores do PCN.

Valor numérico do PCN

\begin{tabular}{l|l}
\hline Tipo de pavimento & Rígido (R) \\
& Flexível (F) \\
\hline \multirow{4}{*}{ Resistência do subleito } & Alta (A) \\
& Média (B) \\
& Baixa (C) \\
& Ultrabaixa (D) \\
\hline \multirow{2}{*}{ Pressão máxima dos pneus } & Alta, sem limite (W) \\
& Média, de 0,1 a $1,5 \mathrm{MPa}(\mathrm{X})$ \\
& Baixa, de 0,51 a $1,0 \mathrm{Mpa}(\mathrm{Y})$ \\
& Ultrabaixa, de 0 a $0,5(\mathrm{Z})$ \\
\hline \multirow{3}{*}{ Método de avaliação } & Técnica (T) \\
& Prática $(\mathrm{P})$. \\
\hline
\end{tabular}

Fonte: Adaptado (FAA, 2011).

A partir do Quadro 2 é possível identificar um tipo específico de pavimento. Caso o pavimento tenha o registro $\mathrm{PCN} 80 / \mathrm{R} / \mathrm{B} / \mathrm{W} / \mathrm{T}$ ele indica que o pavimento tem o PCN de 80, rígido, com uma resistência no subleito média, aceita altas pressões nos pneus e foi avaliado de forma técnica (Durán, 2015).

Entretanto, a FAA (2011), orienta que o método de ACN/PCN seja utilizado apenas para nortear as autoridades em relação a definir a viabilidade de pousos e decolagens de acordo com a capacidade de carga nos pavimentos dos aeródromos e não tem a função de substituir outros procedimentos e estudos que são utilizados para projetar e avaliar as estruturas dos pavimentos aeroportuários.

Vale salientar que experimentos e estudos específicos de cada aeródromo são mais abrangentes e extensos podendo colaborar melhor para a caracterização do novo pavimento.

\section{Considerações finais}

Cada pavimento possui características diferentes. Mesmo possuindo uma estrutura básica comum a todos, os pavimentos são concebidos com características que irão possibilitar o seu melhor aproveitamento e vida útil. Identificou-se que os pavimentos são estruturas destinadas a melhoria do trânsito e segurança dos que o utilizam.

Foi possível identificar a composição dos pavimentos aeroportuários e suas diferenças em relação aos pavimentos rodoviários. Também foram apontados os tipos de pavimentos, revestimentos e suas particularidades como objetivos propostos pelo trabalho. Através desse trabalho será possível desenvolver novas análises e estudos que possam determinar fatores 
positivos e negativos desses tipos de pavimentos e que poderão ser utilizados em pavimentos rodoviários melhorando a qualidade das estradas brasileiras.

Com isso, todos os objetivos postos no trabalho foram alcançados. A composição e particularidades dos pavimentos aeroportuários foram identificadas e expostas juntamente com o traçado de um paralelo entre esse tipo de pavimento e o rodoviário.

\section{Referências}

ANAC. (2008). Resistência de pavimentos aeroportuários. Agência Nacional De Aviação Civil (ANAC). IAC 157_1001.

Balbo, J. T. (2007). Pavimentação Asfáltica: materiais, projetos e restauração. São Paulo: Oficina de Textos. 558 p. il.

Bernucci, L. B. et al. (2006). Pavimentação Asfáltica: Formação básica para engenheiros. Rio de Janeiro: Petrobras: Abeda.

Bernucci, L. B. et al. (2008). Pavimentação Asfáltica: Formação básica para engenheiros. Rio de Janeiro: Petrobras: Abeda.

Brochado, M. M. L. (2014). Estudo da viabilidade do asfalto pré-misturado a frio em rodovias de médio e baixo tráfego. Faculdade De Tecnologia E Ciências Sociais Aplicadas FATECS. Curso: Engenharia Civil. Brasília.

Duran, J. B. C. (2015). Sistema de Gerência de Pavimentos Aeroportuários: Estudo de Caso no Aeroporto Estadual de Araraquara. Dissertação (Mestrado) - Escola de Engenharia de São Carlos da Universidade de São Paulo.

INFRAERO. (2016). Concessão de Aeroportos. Empresa Brasileira De Infraestrutura Aeroportuária (INFRAERO). Acesso em: 30/04/2020.

Disponível em: http://www.infraero.gov.br/index.php/transparencia/concessao.html.

FAA. (1995). Airport Pavement Design and Evaluation - AC No. 150/5320-6D. Federal Aviation Administration. U.S. Department of Transportation. Washington, DC, USA. 
FAA. (2019). Dimensionamento de pavimentos aeroportuários rígidos e flexíveis. Software FAARFIELD (FAA Rigid and Flexible Iterative Elastic Layer Design). Federal Aviation Administration. U.S. Department of Transportation. Disponível em: https://www.faa.gov/airports/engineering/design_software/. Acesso em: 01/05/2020.

FAA. (2007). Guidelines and Procedures for Maintenance of Airport Pavements. Advisory Circular - AC 150/5380-6A. Federal Aviation Administration. U.S. Department of Transportation. Washington, DC.

FAA. (2011). Standardized Method of Reporting Airport Pavement Strength - PCN. Advisory Circular - AC 150/5335-5B. Federal Aviation Administration. United States United States Department of Transportation . Washington, DC.

Garcia, S. J. et al. (2014). Aeroportos. Engenharia civil. Universidade Paulista (UNIP). Trabalho referente ao Seminário do curso de Engenharia Civil do $9^{\circ}$ semestre, disciplina Engenharia Civil Integrada. Araçatuba-SP.

Gil, A. C. (2009). Como elaborar projetos de pesquisa. São Paulo: Atlas.

Gomes, A. F. S. S. (2008). Tecnologia Aplicada à Avaliação das Estruturas dos Pavimentos Aeroportuários. Monografia (Especialização) - Centro de Formação de Recursos Humanos em Transportes, Universidade d Brasília, DF.

Guiadotrc. (2014). Fichas técnicas de pneus comerciais. GT Guia do Transportador. Acesso em 30/04/2020. Disponível em:

www.guiadotrc.com.br/Gestao_Frotas/pneus_fichatecnica.asp.

International Civil Aviation Organization (ICAO). (2013). Aerodrome Design and Operations. Annex 14, Aerodromes. 1v., 6. Ed.

Medina, J. \& Motta, L. M. G. (2005). Mecânica dos Pavimentos. Universidade Federal do Rio de Janeiro. 2 ed. Rio de Janeiro - RJ. 
Michelin. (2014). Aircraft tire Engineering. Data. Data Book. Acesso em 30/04/2020.

Disponível em: http://www.airmichelin.com/generalcontent.aspx?id=219.

Nogueira, C. (1961). Pavimentação: projeto e construção. Rio de Janeiro: Ao Livro Técnico.

Oliveira, F. H. L. (2009). Proposição de Estratégias de Manutenção de Pavimentos Aeroportuários Baseadas na Macrotextura e no Atrito: Estudo de Caso do Aeroporto Internacional de Fortaleza. Dissertação (Mestrado) - Programa de Mestrado em Engenharia de Transportes, Universidade Federal do Ceará, Fortaleza, CE.

Pereira, A.S. et al. (2018). Metodologia da pesquisa científica. [e-book]. Santa Maria. Ed. UAB/NTE/UFSM. Acesso em: 1 maio 2020. Disponível em:

https://repositorio.ufsm.br/bitstream/handle/1/15824/Lic_Computacao_MetodologiaPesquisa-Cientifica.pdf?sequence $=1$.

Ramos, B. A. S. Lima, D. C. Pitanga, H. N. \& Silva, T. O. Aplicação de métodos de dimensionamento de pavimentos aeroportuários da FAA ao Aeroporto Internacional Presidente Juscelino Kubitschek. Revista Transportes. Disponível em: www.revistatransportes.org.br. Acesso em: 01/05/2020.

Senço, W de. (2001). Manual de Técnicas de Pavimentação. vol. 1. 2. ed. São Paulo: Pini. Senço, W. (2008). Manual de Técnicas de Pavimentação: Volume I. 2.ed. S.Paulo: PINI. Taffe. E. J. (2002). Uma Alternativa Econômica quanto ao Dimensionamento de Pistas de Aeródromos. Anais do VII Encontro de Iniciacão Científica do Instituto Tecnológico da Aeronáutica, ITA. São José dos Campos, SP.

Vicentini, D. F. (2017). Aeroportos. Pavimentos aeroportuários. Universidade Federal do Paraná. Setor de Tecnologia. Departamento de Transportes. 
Research, Society and Development, v. 9, n. 7, e180972510, 2020

(CC BY 4.0) | ISSN 2525-3409 | DOI: http://dx.doi.org/10.33448/rsd-v9i7.2510

Porcentagem de contribuição de cada autor no manuscrito

Ramon de Souza Ferreira - 40\%

Nádia Maria Dias Lopes - $40 \%$

Paulo Henrique Vieira de Carvalho - 20\% 